\title{
Hospital infection yesterday and today
}

\author{
MARY BARBER
}

From the Postgraduate Medical School of London

\section{HISTORICAL BACKGROUND}

BEFORE LISTER

Cross infection has been a problem throughout the ages wherever the sick have been housed. It was particularly rife in some of the larger hospitals of Europe in the centuries before Lister, making all but the most imperative operations unthirkable. Paré in the sixteenth century complained that infection at the Hôtel Dieu in Paris was so frightful that no operation could rightly be contemplated in that institution.

The graphic accounts of John Bell at the beginning of the nineteenth century paint a horrifying picture.

'There is no hospital,' he wrote (1801), 'however small, airy or well regulated, where this epidemic ulcer is not to be found at times; and then no operation dare be performed! every cure stands still! every wound becomes a sore, and ever sore is apt to run into gangrene: but in great hospitals especially, it prevails at all times and is a real gangrene; it has been named the Hospital Gangrene; and such were its ravages at the Hôtel Dieu of Paris (that great storehouse of corruption and disease) that the surgeons did not dare to call it by its true name.'

John Bell saw no solution to the problem.

'What then, is the surgeon to do?' he continues. 'Is he to seek for washes or dressings to cure such a disease as this? Is he to expend butts of wine, contending, as it were, against the elements? No! Let him bear this always in mind, that no dressings ever have been found to stop this ulcer; that no quantities of wine or bark which a man can bear have ever retarded this gangrene; let him bear in mind that this is a hospital disease; that without the circle of the infected walls the men are safe; let him, therefore, hurry them out of this house of death ... let him lay them in a schoolroom, a church, on a dunghill or in a stable . . . let him carry them anywhere but to their graves.'

\section{FROM ANTISEPTICS TO ANTIBIOTICS}

This hopeless attitude towards hospital sepsis persisted for another 50 years, until Lister demonstrated its microbial origin and proved to the world that it was a preventable disease. His antiseptic tech- nique was first applied in 1865 . The dramatic effect and the consequent revolution in surgery are well known.

In the years that followed, asepsis largely superceded antisepsis and enormous improvements in hospital, particularly theatre, hygiene were introduced. By about the 1930s the conquest over hospital infection seemed almost complete and operations which would not have been contemplated in the days of Lister became everyday occurrences. Admittedly 'clean' operations still sometimes became infected, but this occurred so much less frequently and with so much less severity than formerly that little attention was paid, and few, if any, surgeons kept a record of the incidence.

In the last 20 years antiseptics of a new type have appeared on the scene, namely antibiotics. Unlike the old-fashioned antiseptics, which are general protoplasmic poisons, antibiotics have a selective toxicity for certain cells and are relatively harmless to others. This important property is, of course, the basis of their therapeutic activity, since they will kill bacteria in doses which do not affect the cells of the human body. But the corollary is that no antibiotic yet discovered attacks all species of pathogenic microbe and among sensitive species individual strains may develop new metabolic pathways which bypass the drug's action. Nevertheless the arrival of penicillin in 1940 seemed at first to be the final answer to hospital cross infection, since it was the death warrant of the two organisms at that time largely responsible, i.e., Strep. pyogenes and Staph. pyogenes.

\section{TWENTY YEARS AFTER}

Unfortunately, early hopes with antibiotics have not been fulfilled. The streptococcus has, indeed, lost much of its menace but not so the more adaptable staphylococcus. So far, as will be discussed below, strains of this organism have become resistant to all the antibiotics in common use and appear to flourish in hospitals as never before. Furthermore, cross infection with Gram-negative bacilli is becoming an increasing problem. There is in fact much evidence to suggest that the situation has changed for the worse. 
INCIDENCE, SEVERITY, AND BACTERIOLOGY OF HOSPITAL INFECTION TODAY

The exact position with regard to the incidence of hospital cross infection is difficult to assess, because it is subject to wide fluctuations, not only in different hospitals and wards, but even in a single ward in the absence of any obvious changes in technique. Nevertheless there seems little room for doubt that hospital infection with Staph. pyogenes and certain coliform bacilli, particularly Ps. pyocyanea, has increased in incidence and severity in the last 15 to 20 years (see Hassall and Rountree, 1959; Finland, Jones, and Barnes, 1959).

There are many reasons why this should be so. To begin with, in the first flush of antibiotic triumph, pathogenic bacteria appeared to be defeated and in many, perhaps most, hospitals aseptic technique was relaxed and isolation wards were put to other purposes. Secondly, patients in hospital today are peculiarly susceptible to infection. They tend to be older and many are kept alive for long periods with conditions, such as leukaemia, which predispose towards infection. Moreover, many of the new lifeprolonging procedures, such as major operations, intravenous therapy, the prophylactic administration of antibiotics and treatment with corticosteroids and antimitotic drugs, themselves help to create favourable conditions for bacteria. Thirdly, some of the drug-resistant organisms, which at present flourish in our hospitals, appear to be of enhanced virulence. Thus our hospitals are full of patients who are highly susceptible to infection and of microbes which lose no time in taking advantage of the situation.

A general picture of the incidence of postoperative sepsis in British hospitals is given in a recent survey by the Public Health Laboratory Service (1960). In a total of 21 hospitals the average incidence was $9.7 \%$, and ranged from 4.7 to $21.8 \%$ in different hospitals. Staph. pyogenes was the commonest aetiological agent; it was isolated from $60 \%$ of the septic wounds and was the only pathogen in $45 \%$. Coliform bacilli were isolated together with staphylococci from $13 \%$ and alone from $17 \%$.

The severity of hospital infection today is indicated by the high incidence of bacteraemia. The most extensive study is that of Finland et al. (1959) from the Boston City Hospital, Massachusetts. They recorded a total increase in the incidence of all types of bacteraemia since 1935 and an increase in mortality since 1947. Analysis of the bacteria responsible showed a remarkable change during the period and the results are summarized below.
BACTERAEMIA DUE TO GRAM-POSITIVE COCCI Like other investigators Finland et al. (1959) noted an increase in the incidence of staphylococcal septicaemia. Thus there were 70 cases in 1935, about twice this number in 1941, and over 200 in each of the years 1955 and 1957. The increasing incidence occurred throughout the period, except for the early years of penicillin (1941-47) during which time there was a slight decline.

The number of cases due to haemolytic streptococci was approximately 50 in 1935 but fell sharply between 1935 and 1941 and remained very low until 1957 when there was a slight rise. The pneumococcus was the most frequent aetiological agent in 1935 when it was responsible for about 100 cases. Thereafter the incidence of pneumococcal bacteraemia remained high and although there was a slight fall in 1955 and 1957, in each of these years there were more than $\mathbf{5 0}$ cases. Only minor fluctuations were noted in relation to Strep. viridans. Finally, enterococci were isolated from no cases in 1935, but from 23 to 36 cases each year after 1947.

BACTERAEMIA DUE TO GRAM-NEGATIVE BACILLI The incidence of bacteraemia due to various Gramnegative bacilli showed even more striking changes. In 1935 the total number of such cases was less than 40 , and about three-quarters of them were due to Bact. coli. In 1947 the total number was about 180, of which 70 were due to Bact. coli, 45 to Bact. aerogenes (which had not been isolated from any cases in 1935), and 40 to Proteus. In all the subsequent years of study these three species were each responsible for from 45 to 60 cases per year. Bacteraemia due to Pseudomonas pyocyanea was rare in 1935 , but the number rose steadily, reaching 20 cases in 1957.

\section{DRUG-RESISTANT STAPHYLOCOCCI IN HOSPITAL}

\section{EMERGENCE OF RESISTANT STRAINS}

PENICILLIN AND TETRACYCLINES The story of the emergence of drug-resistant staphylococci in hospitals over the past 20 years is well known. Phagetyping studies have shown that, whatever the ultimate mode of origin of such strains, selection has been the major factor in their increasing incidence in hospital (see Barber, Hayhoe, and Whitehead, 1949; Rountree and Thomson, 1949). With the widespread use first of penicillin in the 1940s and then of the tetracyclines in the 1950s the hospital staphylococci have in fact been passaged from patient to patient in the presence of these antibiotics one after the other. 
Staphylococci do not readily become resistant to either penicillin or the tetracyclines and both cross infection and the widespread use of these drugs have played a part in the emergence of strains of staphylococci resistant to them. Even with both factors operating, penicillin-resistant staphylococci were uncommon until penicillin had been freely available in hospitals for several years. By 1946, however, they were becoming quite frequent (Barber, 1947) and a few years later in hospitals all over the world they outnumbered penicillin-sensitive strains (see Barber and Rozwadowska-Dowzenko, 1948; Rountree and Thomson, 1949; Nichols and Needham, 1949 and many others). Today penicillin-resistant staphylococcal infection is common even in hospital outpatients (MacFarlane, Murrell, Shooter, and Curwen, 1960).

The story was more or less repeated with the tetracyclines except that by the time the latter were introduced, most hospital staphylococci were already resistant to penicillin and it was these penicillinresistant strains which became resistant to the tetracyclines. Thus by 1952 , in many hospitals at least, a few strains of Staph. pyogenes resistant to penicillin and the tetracyclines were responsible for most of the staphylococcal infections (Clarke, Dalgleish, and Gillespie, 1952; Rountree and Thomson, 1949; Lowbury, Topley, and Hood, 1952; Kirby and Ahern, 1953).

STREPTOMYCIN The story with streptomycin and chloramphenicol, both of which were introduced into hospitals between penicillin and the tetracyclines, has been rather different, simply because for different reasons the use of both drugs has been limited. In the case of streptomycin, this was because early studies proved that nearly all species of bacteria could become resistant to its action with unparalleled rapidity. It is not surprising, therefore, that in spite of restriction in its use, many hospital staphylococci are resistant to streptomycin as well as to penicillin and the tetracyclines.

CHLORAMPHENICOL has been kept in reserve, because of its potential danger to the bone marrow. Before this danger was appreciated chloramphenicolresistant staphylococci were emerging in many hospitals, particularly in the U.S.A., but when the use of the antibiotic was no longer widespread the trend was reversed (see Kirby and Ahern, 1953) and until very recently chloramphenicol-resistant staphylococci were uncommon. In the last year or two, however, chloramphenicol has been used more extensively on account of its antistaphylococcal properties, and chloramphenicol-resistant strains are beginning to appear.
ERYTHROMYCIN was introduced into hospitals after we had become aware of the problem of drugresistance and in most places has been kept in reserve. This has had the desired effect and staphylococci resistant to erythromycin are not very common. But since staphylococci develop resistance to erythromycin more readily than to any other antibiotic except streptomycin (Hobson, 1954; Garrod and Waterworth, 1956), erythromycin-resistant strains are by no means unknown, even in hospitals where the drug has been used sparingly. Where it has been widely used the spread of erythromycin-resistant strains in the hospital has been rapid in the extreme (Lepper, Moulton, Dowling, Jackson, and Kofman, 1953).

ERYTHROMYCIN-LIKE ANTIBIOTICS Several antibiotics closely similar to erythromycin are in use, of which the most important are spiramycin and oleandomycin. With all three there is considerable cross-resistance. Between spiramycin and oleandomycin this appears to be complete, but Garrod (1957) has shown that cross-resistance between these two and erythromycin may be dissociated. Thus while strains habituated to erythromycin in vitro always show cross-resistance to spiramycin and oleandomycin this is not always the case with erythromycinresistant strains isolated from patients. With another related drug, E129, resistance is more slowly developed but once again there is some crossresistance with erythromycin.

NOVOBIOCIN Staphylococci become resistant to novobiocin almost, but not quite, as readily as to erythromycin, and resistant strains have been recorded both in vitro (Lin and Coriell, 1956; Garrod and Waterworth, 1956) and in vivo (Nichols and Finland, 1956).

MULTIPLE RESISTANCE Erythromycin and novobiocin-resistant staphylococci encountered in hospitals are usually also resistant to penicillin and tetracycline, since the former antibiotics are mainly used in the treatment of infections resistant to the two latter.

CELBENIN (BRL 1241) This antibiotic is a 'penicillin' which is resistant to staphylococcal penicillinase although it stimulates production of the enzyme. Staphylococci resistant to benzyl penicillin (penicillin G) are sensitive to it (Rolinson, Stevens, Batchelor, Wood, and Chain, 1960), and early reports indicate that staphylococci are not readily rendered resistant to it by passage in vitro (Rolinson et al., 1960; Knox, 1960). It is moreover argued on theoretical grounds that since the only form of resistance to benzyl 
penicillin shown by fully virulent staphylococci is that associated with penicillinase production, celbenin-resistant staphylococci will not become a clinical problem.

Two lines, of objection can be raised to this argument. First staphylococci might produce a new or adapted enzyme which inactivates celbenin. This possibility is supported by the fact that celbenin is not wholly resistant to the penicillinase of $B$. cereus. Secondly, celbenin is not equivalent to penicillinaseresistant benzyl penicillin, since penicillin-sensitive bacteria, including staphylococci, are 20 to 50 times less sensitive to celbenin than to benzyl penicillin. Thus is it possible that the mode of action of celbenin differs in some way from that of benzyl penicillin and that bacteria may develop different pathways of resistance.

Whatever the theoretical arguments, in preliminary experiments I have trained two penicillinase-producing staphylococci to be resistant to from 50 to $100 \mu \mathrm{g} . / \mathrm{ml}$. celbenin; neither strain inactivates the antibiotic, but unlike staphylococci trained in vitro to be tolerant to benzyl penicillin they have retained the typical cultural appearances of Staph. pyogenes and full coagulase and alpha-toxin activity. Whether celbenin-resistant strains will appear in vivo remains to be seen, but it is too early to assume that this cannot happen.

OTHER ANTIBIOTICS Two relatively recent antistaphylococcal antibiotics, vancomycin and ristocetin, so far have a clean record with regard to resistance. This may be partly due to the fact that since both drugs have to be given intravenously and are toxic to the eighth nerve they have been used sparingly, but, at least with vancomycin, laboratory studies have shown that resistance is not readily achieved (Garrod and Waterworth, 1956). Another new antibiotic, kanamycin, is closely related to streptomycin, and although staphylococci do not develop resistance quite so readily to kanamycin as to streptomycin there is some cross-resistance between the two antibiotics.

\section{MODE OF ORIGIN AND FREQUENCY}

\section{OF DRUG-RESISTANT STAPHYLOCOCCI}

DRUG DESTRUCTION Penicillin-resistant staphylococci isolated from infective processes almost invariably owe their resistance to the production of the enzyme penicillinase which inactivates all the penicillins available for therapy (benzyl penicillin, phenoxymethyl penicillin, broxil) except celbenin. Penicillinase production is a relatively permanent property, but many penicillinase-producing strains tend to yield a proportion of cells which have com- pletely lost the capacity (Barber, 1949; Bondi, Kornblum, and De Saint Phalle, 1953; Fairbrother, Parker, and Eaton, 1954). This loss in enzyme production is sudden and complete and suggests spontaneous mutation. It seems likely, therefore, that the gain in enzyme production also occurs by spontaneous mutation, but since the change has not been inequivocally demonstrated in vivo or in vitro the mutation must be a rare one.

On the other hand, staphylococcal penicillinase is an adaptive enzyme, in the sense that the enzyme production of penicillinase-producing strains is increased by the presence of the substrate penicillin, although penicillin does not initiate penicillinase production de novo by penicillin-sensitive staphylococci. Thus the effect of penicillin on the emergence of penicillinase-producing organisms cannot be entirely overlooked.

DRUG TOLERANCE With all other antibiotics, resistant mutants are capable of growing in the presence of unchanged antibiotic. Such strains almost certainly arise by single or multi-step mutation (see Luria and Delbrück, 1943; Demerec, 1945, 1948; Lederberg and Lederberg, 1952). With streptomycin, gross resistance is the result of a single mutation, and the rate of mutation is very high (of the order of 1 in $10^{9}$ or $10^{10}$ cell generations). With the other antibiotics in common use against the staphylococcus, gross resistance is the result of multi-step mutation involving a number of genes. With erythromycin and novobiocin the resistant mutants are so frequent that a gross change in sensitivity develops after only a few passages in the antibiotic in vitro and is often seen in a strain during the treatment of a single patient. With chloramphenicol and the tetracycline antibiotics the mutation rates are much lower. With vancomycin and ristocetin resistant mutants either do not occur or are very rare.

VIRULENCE OF MULTIPLE RESISTANT STAPHYLOCOCCI

Drug-resistant strains isolated in vitro often show an associated reduction in rate of growth and sometimes virulence, so that they may be at a competitive disadvantage with drug-sensitive cultures. But the drug-resistant staphylococci selected in hospitals are those which have survived in the tissues of infected patients and which have been passaged in the hospital community. They are thus likely to be of enhanced virulence and with some strains at least this appears to be the case. Certainly all strains responsible for epidemics in hospitals today are drugresistant and in the large experience of Williams (1959) usually belong to only about six phage types. Thus all hospitals appear to have become breeding 
grounds for a few highly virulent strains of staphylococci, and in devising preventive measures it is important to concentrate on these strains. The recent observation of Moore (1960) that these strains tend to be mercury resistant, if confirmed, offers a quick method for their detection.

\section{STAPHYLOCOCCI IN SURGICAL WARDS}

Many studies of post-operative infection over the last five years have shown that the staphylococci responsible for nearly all cases of surgical crossinfection are strains resistant to penicillin and tetracycline and belonging to phage group III or type 80 , although such strains are relatively uncommon among staff carriers (Alder, Gillespie, and Thompson, 1955; Barber and Burston, 1955; Shooter, Smith, Griffiths, Brown, Williams, Rippon, and Jevons, 1958; Williams, 1959). Often a few strains appear to be responsible for nearly all the infections in a given hospital. Thus in a study by Shooter and his colleagues (1958) of a surgical ward over a period of eight months 186 different types of Staph. aureus were isolated but only 13 caused disease and only three were responsible for sepsis in more than one patient.

In a recent investigation of the surgical wards at Hammersmith Hospital (Barber, et al., 1960) lasting more than two and a half years and involving over 5,000 patients, evidence was accumulated to indicate that some of the multiple resistant strains of Staph. pyogenes in the hospital had enhanced virulence, both in their capacity to initiate infection and in the severity of the infection produced. Thus the ratio of infections caused by staphylococci sensitive to all antibiotics or resistant to penicillin only was 1.4 whereas with strains resistant to penicillin and tetracycline it was 2.0 and with strains resistant to penicillin, tetracycline, and erythromycin it was 3.0. Moreover all but five of 49 generalized infections seen and all but one of the 24 fatal cases were due to multiple resistant strains, although such strains were only responsible for $50 \%$ of the total number of infections.

\section{STAPHYLOCOCCI IN MATERNITY WARDS}

Staphylococcal infection in babies in maternity wards differs from that in surgical wards in that the infecting strains are usually penicillin-resistant staphylococci of phage group I. Such strains also predominate among nurse nasal carriers (Alder et al., 1955; Barber and Burston, 1955). In maternity units they are responsible for infection of the anterior nares and skin of healthy babies as well as for most cases of mild neonatal sepsis (Barber, Wilson, Rippon, and Williams, 1953; Barber and Burston, 1955; Anderson and Williams, 1956).
More severe outbreaks of neonatal infection are, however, sometimes due to multiple resistant staphylococci of phage group III (Beavan and Burry, 1956) or type 80 (Rountree and Freeman, 1955).

\section{SOURCES OF PATHOGENIC STAPHYLOCOCCI}

PRIMARY SOURCE The most important source of pathogenic staphylococci in hospitals is staphylococcal sepsis. Staphylococci in open lesions are more readily disseminated than carrier strains, and, as indicated by studies in surgical wards, tend to be of greater virulence. Nevertheless staff carriers represent an important source, particularly in maternity units. In most cases the main site of carriage is the anterior nares, but in some cases Staph. pyogenes may be persistently present on skin sites, particularly in the perineal region, in the absence of nasal carriage (Hare and Ridley, 1958).

SECONDARY SOURCES From infected patients and carriers staphylococci are readily spread to the environment. Patients with staphylococcal lesions invariably contaminate their bedding and during bed making the staphylococci are widely disseminated throughout the ward. Equally members of the staff who have lesions or are carriers contaminate their clothing, their handkerchiefs, and their hands. Moreover nurses' and doctors' hands or uniform may become contaminated from contact with an infected patient or his bedding.

From any or all of these sources staphylococci may get into the air and dust of wards and operating theatres. As might be expected staphylococci are far more prevalent in the atmosphere of wards than that of operating theatres and wounds are far more often infected in wards than in the operating theatre. On the other hand the important studies of Gillespie and his colleagues at Bristol have shown that theatre infection when it does occur is liable to be more severe (Gillespie, Alder, Ayliffe, Bradbeer, and Wypkema, 1959).

\section{GRAM-NEGATIVE BACILLI IN HOSPITAL}

\section{INCREASING INCIDENCE OF GRAM-NEGATIVE INFECTIONS}

Long before the age of antibiotics it was known that wounds in hospital might become contaminated with Gram-negative bacilli. Meleney (1948) in a Treatise on Surgical Infections analysed the incidence of various bacteria in clean operation wounds during a period of eight years largely before the introduction of antibiotics. Staph. aureus was the commonest in- 
vader and was found in $36 \%$ of the infected wounds. Gram-negative bacilli were isolated from $10 \%$, and consisted of 'Coli' group 6\%, Proteus 3\%, Pseudomonas $1 \%$.

In 1944, Miles drew attention to the possible increase in importance of coliform infections now that efficient weapons (sulphonamides and penicillin) had been found for fighting pyogenic cocci. Three years later Florey, Ross, and Turton (1947) published an important study of the incidence and significance of Gram-negative bacilli in wounds of airborne casualties admitted to the Radcliffe Penicillin Unit. All the patients had received prophylactic injections of penicillin for up to three weeks after wounding, so that pyogenic cocci were relatively uncommon. A total of 1,164 swabs were taken at intervals from 63 deep and 10 superficial wounds. The percentage of the swabs yielding various bacteria was as follows:

\begin{tabular}{lcc} 
& Deep Wounds & $\begin{array}{l}\text { Superficial } \\
\text { Wounds }\end{array}$ \\
\hline Bact. coli & $35 \cdot 4$ & $11 \cdot 5$ \\
Proteus & $36 \cdot 1$ & 17.2 \\
Ps. pyocyanea & $39 \cdot 2$ & 17.2 \\
Staph. aureus & 14.9 & $44 \cdot 8$ \\
Strep. haemolyticus & $4 \cdot 3$ & 0.6 \\
Clostridia & $11 \cdot 3$ & $0 \cdot 0$ \\
Indifferent cocci & $12 \cdot 4$ & 21.9 \\
Sterile & $11 \cdot 7$ & 17.8
\end{tabular}

The presence of coliform organisms appeared to be the result of cross infection in the unit. Bact. coli was the earliest invader and was present in $50 \%$ of all wounds examined in their first week. Proteus appeared most often in the second week and $P S$. pyocyanea in the third. By the end of six weeks, in spite of a no-touch dressing technique, all but one of the 38 still unhealed wounds had been infected with Bact. coli and all but six with Ps. pyocyanea.

Of a number of agents used for local treatment streptomycin was the most effective against all three species, although Eusol and Milton were almost as effective as streptomycin against $P$ s. pyocyanea. An interesting observation was the effect of contamination with Staph. aureus. In many instances there was a steady disappearance of Gram-negative bacilli after the appearance of staphylococci in the wound. If not removed, the main effects of coliform organisms in the wound were lysis of surrounding clot, persistence of discharge, and consequent delay in bony and soft tissue repair.

\section{CHANGING PATTERN OF GRAM-NEGATIVE INFECTIONS}

Since the arrival of the broad-spectrum antibiotics there has been a qualitative change in the type of Gram-negative bacilli responsible for infections. Yow as early as 1952 noted a relative increase in the incidence of Proteus and Pseudomonas infections. Thus a comparison of the Gram-negative bacilli isolated from specimens received in the bacteriological laboratory of a large general hospital in the U.S.A. in June, 1948, and January, 1951, showed that the proportion of Bact. coli fell from 50 to $20 \%$, whereas that of Proteus rose from 8 to 32 and Pseudomonas from 15 to 30 . The same investigation recorded 28 infections, including four bacteraemias due to Pseudomonas, and 19, with two bacteraemias, due to Proteus, occurring in patients under antibiotic therapy. Finland et al. (1959) noted a similar increase in the incidence of Proteus and Ps. pyocyanea in patients with bacteraemia and meningitis.

INCREASING INCIDENCE OF

PS. PYOCYANEA IN HOSPITALS

Among the Gram-negative bacilli, Ps. pyocyanea is the most serious menace and is beginning to rival Staph. pyogenes as the hospital scourge. Not only is it being found with increasing frequency in all kinds of infections in hospital, but the infections tend to be severe and, since there is no really effective chemotherapy, have a high mortality, reaching almost $100 \%$ in cases of established septicaemia.

The frequency with which burns become infected with Ps. pyocyanea is well known (Colebrook, Duncan, and Ross, 1948; Jackson, Lowbury, and Topley, 1951; Markley, Gurmendi, and Chavez, 1957). Apart from the resultant delay in healing and the failure of skin grafts, in extensive burns, Ps. pyocyanea is liable to invade the blood stream and is a common cause of death (Liedberg, Reiss, and Artz, 1954; Markley et al., 1957).

The incidence of Ps. pyocyanea in operation wounds has not often been recorded, but many bacteriologists have the impression that it is on the increase. Figure 1 shows the number of patients in a large London hospital from whom Ps. pyocyanea was isolated from specimens of sputum or pus (mainly infected wounds) between 1958 and 1960. The analysis was undertaken because a very large increase in the number of specimens yielding Ps. pyocyanea was noted in the first quarter of 1958 . The biggest change was the number of patients in the medical wards with Ps. pyocyanea in the sputum. Thus in the first quarter of 1958 there were two such patients, whereas in the first quarter of 1959 there were 39. During the same period the incidence of wounds infected with Ps. pyocyanea in the surgical wards rose from two to 21 . In the summer, as might be expected, the number of patients with Ps. pyocyanea in the sputum fell; in the following winter the number again increased, but probably because 


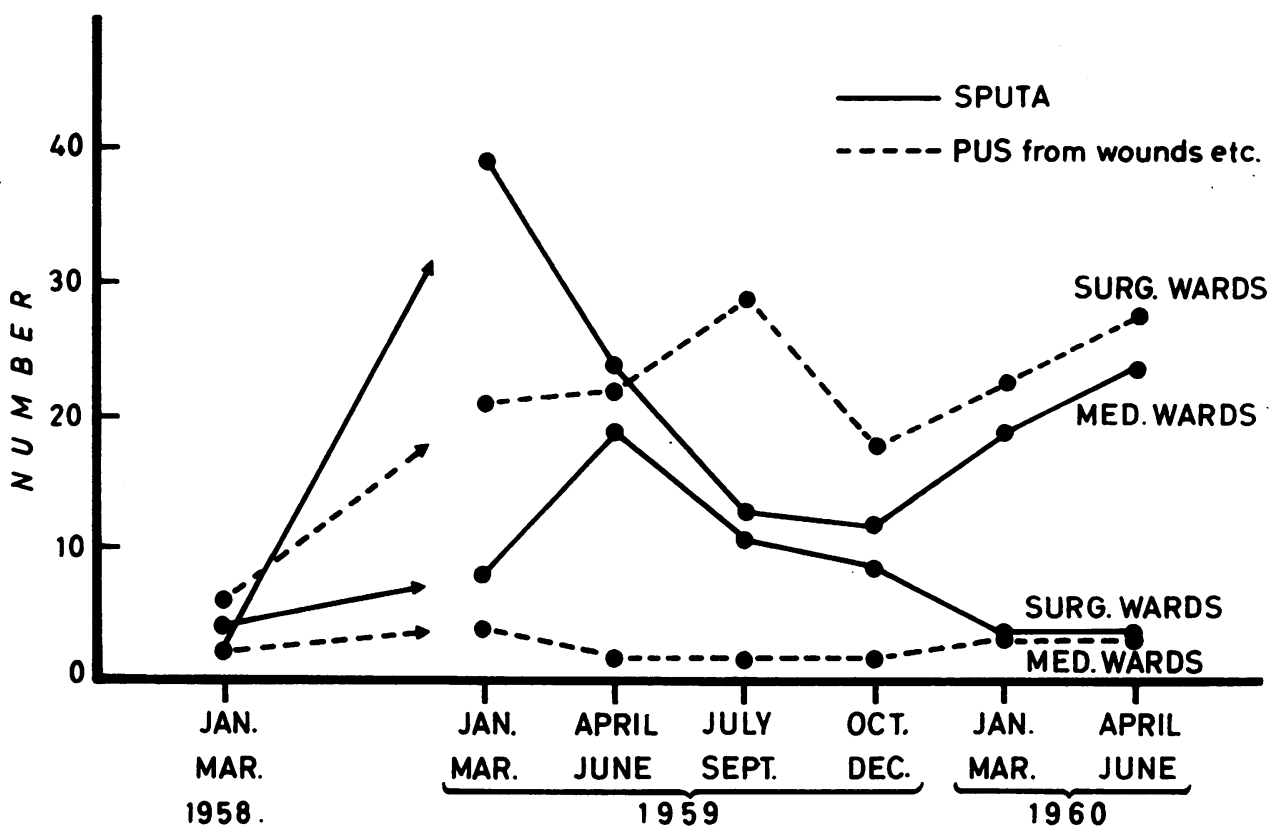

FIG. 1. Infections due to Ps. pyocyanea in a large general hospital.

the weather was much less severe, only to half the number of the previous winter. Wound infections in the surgical wards have remained between 20 and 30 since the sharp rise in the first quarter of 1959.

Many of the medical patients with pseudomonas chest infections were patients with chronic bronchitis, who had had various forms of chemotherapy and were admitted to the wards already infected with $P s$. pyocyanea. Since isolation facilities were not available they were admitted to open wards and it seems possible that they acted as a reservoir of infection in the hospital.

\section{PSEUDOMONAS SEPTICAEMIA IN MEDICAL WARDS}

In recent years pseudomonas septicaemia has been becoming an increasing problem in medical wards, particularly in units devoted to patients under modern forms of treatment for leukaemia. Forkner, Frei, Edgcomb, and Utz (1958) recorded 23 patients with pseudomonas septicaemia between 1954 and 1957, of whom 22 died. Sixteen of the patients had leukaemia, and of 13 who were studied more carefully, 10 had had previous treatment with antibiotics, eight with steroids, and nine with antimetabolite drugs. The same authors analysed the bacteria responsible for 63 septicaemias in the leukaemia service and found that Ps. pyocyanea was second only to the staphylococcus as the aetiological agent. Williams, Williams, and Hyams (1960) recorded three septicaemias, one chest infection, and one intestinal infection due to Ps. pyocyanea, all occurring in a single general medical ward between May and September, 1958. All five patients died and infection with Ps. pyocyanea in all cases materially contributed to their death. Of the three patients with septicaemia, two had leukaemia and the third marrow aplasia. All five patients had previously been treated with broadspectrum antibiotics and all had received corticosteroids.

PRIMARY AND SECONDARY SOURCES OF PS. PYOCYANEA IN HOSPITAL

PRIMARY SOURCE The most important primary source of Ps. pyocyanea, as of Staph. pyogenes, is infected patients. Unlike the staphylococcus, Ps. pyocyanea is rarely carried in the nose or on the skin of healthy individuals, but Lowbury and Fox (1954) isolated Ps. pyocyanea from the stools of two out of 64 medical students.

SECONDARY SOURCES Lowbury and Fox (1954) made an extensive study of the distribution of Ps. pyocyanea in the environment of a burns unit. They 
isolated the organism from the nose and skin of a small proportion of the staff and patients of burns wards, but not from the staff of other wards.

Of the inanimate sources, dust seems to be the most important; $94 \%$ of samples from the burns wards and $16 \%$ from other surgical wards contained Ps. pyocyanea. The percentage of air samples yielding the organism was $86 \%$ during the dressing of an infected wound in the burns dressing station, $27 \%$ in the burns ward during bed making, and $25 \%$ when the ward was at rest. Ps. pyocyanea was also frequently isolated from the outside of bandages and the bedclothes of infected patients, and less frequently from objects brought to the patients, such as bedpans, wash basins, food trays, and toys.

In a recently described outbreak, involving eight patients in an orthopaedic ward, infection was traced to contaminated cellulose wadding used for padding plaster casts applied to fractures (Sussman and Stevens, 1960).

\section{PREVENTION}

As pointed out by Lister, hospital infection is a preventable disease. That it has not yet been prevented is largely a reflection on the fact that in the past we have underestimated the enemy. If we are to succeed we must attack the problem on many fronts. Different modes of attack and their effects are described in detail in the subsequent articles of this series. Here it is only possible to outline the strategy.

The first line of attack must be on the primary human reservoirs of infection. Infected patients must be excluded from open general wards and the infection controlled, where possible, by means of intelligent chemotherapy. With staphylococci, nasal and skin carriers have also got to be considered. To what extent this would remain necessary once the cycle of cross infection had been broken by the strict isolation of infected patients remains to be determined. But at present there is no doubt that carriers, at any rate of multiple resistant staphylococci, can be a source of danger.

Staph. pyogenes, Ps. pyocyanea, and other drugresistant coliform bacilli in the hospital environment must also be dealt with. This entails rigorous aseptic technique in wards as well as in theatres, clean air, clean bedding, and hygienic methods of dust removal.

Last, but not least, some control of the use of antibiotics in hospitals is essential both to prevent the emergence of drug-resistant bacteria and also to avoid rendering patients more susceptible to infection by such bacteria, through elimination of the normal flora.

Money will have to be spent, but let us bear in mind that at present it is being wasted. In a recent survey by the Public Health Laboratory Service (1960) it was estimated that the cost of post-operative sepsis to the National Health Service is some $£ 5$ million per annum, quite apart from the value of any lives lost. To return to the words of John Bell (1801):

'No expense should be spared ... you would willingly expend your own future in such a cause-then do not grudge to employ the revenue of the state for it is employing it and not abusing it! ... if in the course of a few weeks sixty men die of the disease in your hospital, government has lost a sum which would trebly buy your hospital itself.'

Cross-infection in hospital has remained a problem yesterday and today. If enough people take it seriously there is no reason why it should continue tomorrow.

\section{REFERENCES}

Alder, V. G., Gillespie,W. A., and Thompson, M. E. M. (1955). J. Path. Bact., 70, 503.

Anderson, E. S., and Williams, R. E. O. (1956). J. clin. Path., 9, 94. Barber, M. (1947). J. Path. Bact., 59, 373.

- (1949). J. gen. Microbiol., 3, 274.

- , and Burston, J. (1955). Lancet, 2, 578.

, Dutton, A. A. C., Beard, M. A., Elwes, P. C., and Williams, R. (1960). Brit. med. J., 1, 11.

—, Hayhoe, J. E. M., and Whitehead, J. E. M. (1949). Ibid., 2, 1120.

—, and Rozwadowska-Dowzenko, M. (1948), Ibid., 2, 641.

—, Wilson, D. B. R., Rippon, J. E., and Williams, R. E. O. (1953). J. Obstet. Gynaec. Brit. Emp., 60, 476.

Beavan, D. W., and Burry, A. F. (1956). Ibid., 2, 211.

Bell, John. (1801). The Principles of Surgery, Vol. 1, Ch. 3. Edinburgh.

Bondi, A., Kornblum, J., and De Saint Phalle, M. (1953). Proc. Soc. exp. Biol. (N.Y.), 83, 527.

Clarke, S. K. R., Dalgleish, P. G., and Gillespie, W. A. (1952). Lancet, $1,1132$.

Colebrook, L., Duncan, J. M., and Ross, W. P. D. (1948). Ibid., 1, 893.

Demerec, M. (1945). Proc. nat. Acad. Sci. (Wash.), 31, 16.

- (1948). J. Bact., 56, 63.

Fairbrother, R. W., Parker, L., and Eaton, B. R. (1954). J. gen. Microbiol., 10, 309.

Finland, M., Jones, W. F., and Barnes, M. W. (1959). J. Amer. med. Ass., 170, 2188.

Florey, M. E., Ross, R. W. N. L., and Turton, E. C. (1947). Lancet, 1,855 .

Forkner, C. E., Jr., Frei, E., Edgcomb, J. H., and Utz, J. P. (1958). Amer. J. Med., 25, 877.

Garrod, L. P. (1957). Brit. med. J., 2, 57.

$\longrightarrow$, and Waterworth, P. M. (1956). Ibid., 2, 61.

Gillespie, W. A., Alder, V. G., Ayliffe, G. A. J., Bradbeer, J. W., and Wypkema, W. (1959). Lancet, 2, 781.

Hare, R., and Ridley, M. (1958). Brit. med. J., 1, 69.

Hassall, J. E., and Rountree, P. M. (1959). Lancet, 1, 213.

Hobson, D. (1954). Brit. med. J., 1, 236.

Jackson, D. M., Lowbury, E. J. L., and Topley, E. (1951). Lancet, $2,137$.

Kirby, W. M. M., and Ahern, J. J. (1953). Antibiot. and Chemother., 3, 831 .

Knox, R. (1960). Brit. med. J., 2, 690.

Lederberg, J., and Lederberg, E. M. (1952). J. Bact., 63, 399.

Lepper, M. H., Moulton, B., Dowling, H. F., Jackson, G. G., and Kofman, S. (1953). Antibiot. Ann., 1953-4, p. 308.

Liedberg, N. C. F., Reiss, E., and Artz, C. P. (1954). Surg. Gynec. Obstet., 99, 151.

Lin, F. K., and Coriell, L. L. (1956). Artis. Med., 2, 268

Lowbury, E. J. L., and Fox, J. (1954). J. Hyg. (Camb.), 52, 403.

- , Topley, E., and Hood, A. M. (1952). Lancet, 1, 1036. 
Luria, S. E., and Delbrück, M. (1943). Genetics, 28, 491.

MacFarlane, D. A., Murrell, J. S., Shooter, R. 4., and Curwen, M. P. (1960). Brit. Med. J., 2, 900.

Markley, K., Gurmendi, G., and Chavez, P. M. (1957). Ann. Surg., $145,175$.

Meleney, F. L. (1948). Treatise on Surgical Infections, pp. 134-135. Oxford Univ. Press, New York.

Miles, A. A. (1944). Lancet, 1, 809.

Moore, B. (1960). Ibid., 2, 453.

Nichols, D. R., and Needham, G. M. (1949). Proc. Mayo Clin., 24, 309

Nichols, R. L., and Finland, M. (1956). Antibiot. Med., 2, 241.

Public Health Laboratory Service. (1960). Ibid., 2, 659.
Rolinson, G. N., Stevens, S., Batchelor, F. R., Wood, J. C., and Chain, E. B. (1960). Lancet, 2, 564.

Rountree, P. M., and Freeman, B. M. (1955). Med. J. Aus., 2, 157

- and Thomson, E. F. (1949). Lancet, 2, 501.

Shooter, R. A., Smith, M. A., Griffiths, J. D., Brown, M. E. A. Williams, R. E. O., Rippon, J. E., and Jevons, M. P. (1958) Brit. med. J., 1, 607.

Sussman, M., and Stevens, J. (1960). Lancet, 2, 734.

Williams, R. E. O. (1959). Ibid., 1, 190.

Williams, R., Williams, E. D., and Hyams, D. E. (1960). Ibid., 1 , 376.

Yow, E. M. (1952). J. Amer. med. Ass., 149, 1184. 